\title{
ORGANIZATION OF EDUCATION OF SCHOOLCHILDREN WITH SPECIAL NEEDS IN SECONDARY SCHOOLS OF GERMAN-SPEAKING COUNTRIES
}

\section{Larysa Kozibroda ${ }^{1}$ \\ Oksana Lypchanko-Kovachyk²}

DOI: https://doi.org/10.30525/978-9934-26-021-6-5

Abstract. The article aims at investigating, analyzing and summarizing the peculiarities of organization of education of schoolchildren with special needs in secondary schools of Germany, Austria, Switzerland. The authors describe the experience of the countries mentioned above. In particular, the national policy of German-speaking countries concerning the integration of people with special educational needs into common socio-educational environment has been considered, the provisions of state and regional regulations governing this process have been highlighted, as well as the key approaches to its organization and practical implementation have been described by the authors of the article under consideration.

The study reveals general ideas and principles of education of children with special needs in secondary schools of Austria, Switzerland, Germany and highlights the specificity of their practical implementation at the legal level of these countries in general and throughout specific regions of each one, in particular.

In the process of the analysis the following methods have been applied: description, generalization, comparison and systematization of psychopedagogical, didactic and methodological researches.

The authors reveal the specific features of the implementation of policies in the field of inclusive schooling, which had been implemented by the governments of developed countries: coverage of all children, despite individual differences or difficulties; adoption of the principle of inclusive

\footnotetext{
${ }^{1}$ Candidate of Pedagogical Sciences,

Associate Professor of the Physical Training Department,

Lviv Polytechnic National University, Ukraine

${ }^{2}$ Candidate of Pedagogical Sciences,

Senior Lecturer of English Philology Department,

Mukachevo State University, Ukraine

(C) Larysa Kozibroda, Oksana Lypchanko-Kovachyk
} 
education in the form of a law or a political declaration; development of demonstration projects and encouragement of exchange of experience with other countries; creation of decentralized and joint mechanisms for planning, monitoring and evaluation of educational services for children and adults with special educational needs; encouraging the participation of parents, communities and organizations of persons with disabilities in the planning and decision-making processes to meet special educational needs; efforts to develop strategies for early identification of such needs, as well as professional aspects of inclusive education; ensuring of the establishment and implementation of teacher training programs to provide education for people with special educational needs in public schools.

It has been concluded that the integration of people with special educational needs into the academic environment of public school involves the recognition and consideration of different opportunities and needs of students, providing different types and rates of learning according to students' abilities, implementing the appropriate organizational structure, teaching and educational strategies, providing necessary additional assistance and support.

\section{Introduction}

Social, political and economic changes in different countries in the late XX - early XXI century caused radical changes in the consciousness of a mankind, especially regarding the system of values, which, in its turn, shapes the future civilization development of the most successful countries in foreign policy.

Many years of struggle against all forms of discrimination in the world have ensured the formation and adoption of a new socio-cultural norm-respect for the diversity of differences between people-racial, ethnic, cultural, and many others. Such transformations of public consciousness have become a powerful impetus to change the attitude towards people with special needs. The history of mankind demonstrates a wide range of ideas in the attitude of the state and society to such people - from hatred, aggression, contempt to tolerance, support, interaction.

The idea of integration of people with special educational needs into the common educational space has been the object of close attention of the world community for the recent decades. It is called today to be 
one of the key priorities of international educational policy embodied in numerous international documents, both normative and recommendatory such as Convention against the discrimination in education (1960), World Declaration on Education for All (1990), Salamanca Statement and Framework for Action on Special Needs Education (1994), etc. These are the result of productive international collaboration and the consensus of the world on the need to overcome discrimination against school systems for people with special educational needs and provide them with qualitative education according to their specific capabilities.

The ratification by the vast majority of countries of the world of international documents in the social and educational spheres, declaring the right of everyone to education without discrimination, has led to the reconsideration of their educational legislation in accordance with international norms, standards and reorganization of national school systems. In recent decades, the governments of the world's leading countries have made necessary effort to legislate the right of to get qualitative education by all children, regardless of individual potential and opportunities, level and characteristics of development, specific educational needs within a common, unified school system and implemented radical reforms to ensure conditions. The significance and importance of these works is confirmed by a number of studies held by Ukrainian scientists (O. Bezpalko, G. Davydenko, M. Zakharchuk, A. Migalush, S. Fedorenko, V. Tarasenko, etc.).

\section{Current views on education of people with special needs}

In the context of the transformation of society's attitude to people with special needs, there was a rethinking of their needs, freedoms, rights, including one of the basic socio-cultural human rights - the right to education. Convincing evidence of this is the Convention against Discrimination in Education (1960), ratified by more than a hundred countries. Based on the right of everyone to education, the document affirms the principle of inadmissibility of discrimination in the field of education on any grounds. In particular, it is a question of preventing the provision of any benefits or restrictions on physical, cultural, ethnic, religious, social, material, etc. features, which involves the destruction or violation of equality in education, such as restricting access to education, limiting educational opportunities, inequality and the quality of educational services, etc. 
In order to eliminate or prevent discrimination, the document obliges governments to repeal all legislative provisions and administrative provisions containing discriminatory provisions and to end administrative practices of discriminatory nature in the field of education, and instead provide conditions for the realization of everyone's right to obtain qualitative education, successful self-realization in various spheres of life. The provisions of the Convention justify education not as a privilege but as a fundamental human right, emphasize the obligations of countries to provide free and compulsory education, eliminate all forms of discrimination and promote equality of opportunity in education. The document comprehensively covers the right to education and is a powerful tool for ensuring fair and quality education for all.

The reform of educational systems, aimed at covering all children with schooling, including those with special needs, should be based on the perception of differences between people as norms, on understanding the need to adapt school and education to children's needs, and not adapting them to pre-established norms and standards. organization and nature of the educational process. A school focused on the needs of children, their individual characteristics, opportunities and needs avoids the waste of resources and the collapse of hopes, which is often the result of the pattern of the educational process. The environment of such a school is a kind of prototype of a people-oriented society, in which there is a respectful attitude to the differences and dignity of all people.

Therefore, the document promotes the implementation of a new approach to the education of people with special educational needs, which ensures their integration into the traditional educational environment and the absolute rejection of their alienation given the difficulties and differences. The work of the school based on this approach should be based on the recognition and consideration of different opportunities and needs of its schoolchildren, providing different types and rates of learning according to their characteristics, implementing the appropriate organizational structure, teaching and education strategy, providing necessary additional help and support. In such circumstances, children with special needs can achieve the highest results in education and social integration, compared to the conditions of a special educational institution, the involvement of which should be an exception, recommended only in rare cases and in cases of extreme necessity. 
The concepts of the education of people with special educational needs is a general guide for planning actions in the field of education of children with special educational needs in order to transform the practice of their involvement in the regular education system into an integral part of national concepts, plans and development programs of education and ensuring the right for education to all. They are of a recommendatory nature and cannot take into account the whole variety of situations regarding the education of children with special educational needs in different regions and countries of the world, and therefore should be adapted and specified depending on local needs and circumstances. They are designed to serve as a basis for national, regional and local action plans that reflect the political idea of the government and the desire of the state and society to provide education to all.

In the context of education of people with disabilities, special emphasis is placed on providing opportunities for their full socialization, in particular, the importance of creating conditions for learning life and social skills to facilitate full and equal participation of persons with disabilities in education and social life. Among the measures to be taken to meet these requirements of the document are: promoting the Braille alphabet, alternative fonts, reinforcing and alternative methods, methods and formats of communication, as well as orientation and mobility skills; creating conditions for learning sign language and encouraging the linguistic identity of the deaf; providing training for people with different types of disabilities through the most optimal languages, methods and ways of communication and in the most favorable atmosphere for the acquisition of knowledge and social development.

\section{Investigated experience of German-speaking countries}

The novelty and value of foreign experience in organization of education of schoolchildren with special needs draws our attention to the achievements obtained in this area, first of all, of those countries in which the relevant practice has already existed for a long time, has become widespread and is characterized by variability of models, unique approaches, effective results.

In this context, it is worth mentioning such leading countries in the world as Germany, Austria, Switzerland, which can be considered as a good example of a combination of generally accepted global approaches and the best national traditions in solving this problem. 
The present article throws light upon the experience in organization of the education of schoolchildren with special educational needs in secondary schools of the mentioned countries.

As it has already been noticed, the idea of including all children, regardless of their physical, mental, intellectual, cultural, ethnic, linguistic, etc. features into unique and common general education system has become one of the key priorities of modern international educational policy. Its implementation allows children to realize the abilities, talents, differences and features of each other, to develop social contacts, to form the ability to interact with each other and with the world around them. This approach to the organization of education promotes awareness of one's own personality and personalities of the others, regardless of origin, state of health or developmental characteristics of a part of the social community and the formation of a sense of belonging to it. It opens wide prospects for fostering tolerance of students without special educational needs, forming their readiness to accept human differences and respect diversity, developing the ability to help each other, as well as awareness of the peculiarities and difficulties of life of people with disabilities. At the other hand, for children with special needs, the idea of learning within in a common general education system creates the preconditions for fuller realization of development potential, active participation in the school community, and in the long run to occupy a worthy niche in society and reduce social inequality [1].

Guided by common global strategies and approaches, each country chooses its own way of solving the problem of education and upbringing of children with special needs, taking into account the existing national educational traditions and achievements. In Germany, the decision to integrate people with special educational needs into the secondary school environment was agreed and approved by the Conference of Ministers of Education and Culture, a special body that coordinates education policy and sets uniform standards for education at the state level, federal states in matters of culture and education. The proposed general recommendations for the integration of schoolchildren with special educational needs into secondary schools became the basis for updating regulations on education and implementing the necessary reforms in all federal states.

In Austria, the problem of social and educational integration of people with special needs at the national level is regulated by the national action plan approved by the government on the implementation of international 
instruments on the rights of people with special needs. The document determines common national strategies for solving this problem and obliges the federal authorities to provide equal quality of educational services for all segments of the population at all levels of the national education system.

In Switzerland, national guarantees of law at the level of educational prospects for representatives of all social groups are established by the relevant cantonal agreement on social support and education of people with special needs, which outlines a range of key measures to ensure their educational and social integration into a single social and educational environment. The document establishes the general mechanisms and tools developed as a result of productive cooperation of delegates from all cantons of the confederation to meet the special educational needs of children and youth within the general education system and the organization of their support in the schooling process.

The establishment of such unified requirements and standards, however, does not limit the possibilities for testing different approaches and models of providing education and upbringing of people with special educational needs in secondary schools, which differ not only at the level of countries but also in regions and administrative units of one country, such as federal states in Austria and Germany or the cantons in Switzerland. Focusing on national norms and requirements, local authorities and structures seek their own ways and means of social and educational integration of people with special needs in the environment of a traditional secondary school in accordance with local characteristics and opportunities.

The German experience of organizing the education of children with special needs within a secondary school will be illustrated by the example of the achievements of the federal state of Schleswig-Holstein, which became a model to follow throughout the whole country. The idea of integrating children with special educational needs into the general school environment is a mandatory norm in this land, enshrined in the relevant provisions of the local law on education - school-age children, despite the presence or absence of special educational needs, must study in general educational institutions with appropriate organizational, material conditions and opportunities to provide individual pedagogical assistance if necessary [6].

In order to implement this provision of the law, new unified curriculum for basic school education have been developed, which are mandatory for implementation in all primary and secondary schools operating on the 
territory of the federal state $[4 ; 5]$. Their main idea is to provide education to all schoolchildren, regardless of their individual characteristics, with the opportunity to fully participate in school and social life. The objective is to develop the mental, spiritual, physical inclinations of each child, his individual abilities in accordance with natural inclinations and needs.

The first direction provides the formation of key competencies of schoolchildren, which are defined in the curriculum as «basic knowledge and ideas, skills and abilities that form the basis of their full life, learning and social activity», physical, mental, moral, behavioral, aesthetic, practical, technical and social skills that are the basis of self-realization in personal and social life. The second area of school activity, aimed at preparing for life taking into account the realities up-to-date world, involves educational work with children on key interdisciplinary topics in the study of school subjects and extracurricular activities that reflect the main problems of modern life:

1. Values (concerning the work on this topic it has been emphasized in the curriculum the children's development of modern ideals and values of human life and coexistence, which are peace, human rights, life in the open world with a wide variety of cultures, religions, nations, etc.).

2. Life and health (educational activity under consideration of this topic has been directed by the curriculum to obtain knowledge about life care, health care, fundamentals of healthy way of life, understanding basic threats for life and health).

3. Science and progress (elaboration of this cross-cutting theme for different school disciplines serves the ground for making scoolchildren to be aware of the chances and risks of scientific and technological progress, its impact on human life, assessment of the consequences for each person in particular and humanity in general).

4. Gender equality (mastering this key topic provides students with an understanding of the importance of achieving equal human rights between men and women in all types of relationships, equalizing their role in society, overcoming discrimination on the basis of gender).

5. Social integration (pedagogical work on this topic in accordance with the curriculum involves awareness of schoolchildren about the rights and needs of each person in active social life, the formation of willingness to participate in it, the ability to share responsibilities, to defeat discrimination on various grounds). 
Achieving these tasks of basic school education in the curriculum is subject to the entire list of traditional school subjects and extracurricular activities implemented in the process of primary and secondary school education.

Special attention in the curriculum is paid to the problems of adaptation of schoolchildren with special educational needs and without them to the conditions of their common school life and learning. In particular, the basic principles of its success are defined as: 1) ensuring constant contacts and dialogue between students with special needs and students without them; 2) explanation of the rules and norms of interaction and cooperation in the school environment; 3 ) demonstration of ways and models of constructive resolution of conflict situations, etc.

For some extra additional support of children with special educational needs in the process of study in the secondary school, a special curriculum has also been developed as a set of clear recommendations and specific programs of individual support for schoolchildren depending upon their characteristics. It is mandatory for implementation in all types of general education institutions that provide educational work with children with special educational needs, regardless of degree, level or type. It serves as a basis for the support and accompaniment of such children in the form of individual assistance on the way to their integration into the usual school environment and in the process of their educational activities. The special curriculum is presented as a supplement to the general curricula of basic school education, and the features of its practical implementation are determined by the degree and intensity of developmental disorders of children, the range of limitations, the form of special needs. In particular, the plan contains valuable recommendations and guidelines for the organization of education in the general education system of children with school adaptation difficulties, mental, speech, social, psycho-emotional, physical development, motility, hearing, vision, autism spectrum disorders. The specifics of the application of this curriculum is determined by the individual state of each child, its urgent needs, current opportunities, and thus provides a variety of options for its implementation in practice.

In order to provide individual assistance and support to children with special educational needs in the process of learning in secondary school, a set of additional educational and developmental programs has been proposed within the special curriculum, including: 
- program of support and correction of development of educational abilities;

- program of support and correction of emotional and social development;

- program of support and correction of speech development;

- program of support and correction of cognitive development;

- program of correction of physical development and motility;

- program of correction of sensor development (sight, hearing);

- program of education of schoolchildren with autism spectrum disorder;

- program of support and development of giftedness.

Special attention in our study has been paid to a program of support and correction of the emotional and social development of children with special educational needs, aimed at overcoming and preventing problems of socioemotional disorders, promoting their integration into the group environment and full socialization. Its purpose is to provide support for schoolchildren with special educational needs on the way to their school adaptation and maximum integration into the social environment of secondary school. The program provides individual assistance to such children in mastering the norms of school and social behavior. The expediency of its development was due to the frequent difficulties of children with special educational needs in the process of their adaptation to school conditions, frequent manifestations of fear, passivity, helplessness, distrust in interaction with peers, solitude and more.

The program of support and correction of emotional and social development provides self-confidence of schoolchildren with special educational needs, learning the rules and regulations of interaction with others, gaining their own experience of establishing and maintaining social contacts, skills of cooperation with other students. To do this, the program provides a wide range of activities, such as a variety of game forms (mobile, role-playing, imitation, etc.), creative activities (drawing, designing, dancing, singing, etc.), sports, competitions, team sports games, etc.).

Hence, the authority's approach in federal state of Schleswig- Holstein towards the problem of integration of schoolchildren with special educational needs in terms of system of general secondary school lies in the abandonment of the traditional system of special education for such schoolchildren and reorganization of special education institutions into child development support centers that provide additional pedagogical, psychological, therapeutic, rehabilitation assistance to children with special 
needs within the family and school or independently provide education and upbringing of such children in particularly difficult situations and cases. And this trend in recent years is quite active throughout Germany.

Achievements of Switzerland in the field of integration of people with special educational needs into the single general educational environment of the country will be demonstrated in the experience of the canton of Basel, which is marked by balanced decisions and systematic measures. The idea of opening a comprehensive school space for all school-age children is declared mandatory by the cantonal law on education - «The task of a comprehensive school is to promote the physical and mental development of all students based on family upbringing to prepare them for a future life. It should provide to schoolchildren some support in finding their personal identity in society, developing the ability to learn throughout life and the formation of responsible behaviors towards themselves, others and the environment» - proclaimed in Art. 3 of the relevant document [6].

One of the tools to implement this idea and norm in law is the need to organize additional proposals for education and support of students given their individual abilities and talents, as well as limited opportunities and special needs. In this way, at the level of the canton of Basel, the secondary school is conceptualized as a school for all, which covers school education of each child in accordance with the educational capabilities and needs.

The organization of the educational process in the canton's secondary schools is based on standard curricula and programs of basic school education, the religious values, humanistic and democratic ideals, neutrality in politics, religions and denominations, gender and social equality and justice. The requirements and standards of these curricula are mandatory for all students in the school, regardless of their specific needs or abilities.

\section{Results of the analysis of academic curriculum}

The academic curriculum divides basic school education into six subject areas, which are socially conditioned and based on cultural and school traditions and norms:

1. Language - supports the development of language and communicative abilities of schoolchildren of the native language (German, French, Italian, Rhaeto-Romance language), one of the state languages of confederation as a foreign language and one more foreign language, usually English. 
2. Mathematics - serves the development of mathematical thinking of students, the ability to understand and evaluate mathematical facts and patterns, to perform mathematical operations.

3. Nature, human, society - acquaints students with the modern world in its natural, technical, historical, cultural, social, economic, ethical and religious dimensions and ways of responsible living in it.

4. Art - forms the ability to aesthetic worldview, personal and value attitude to art and skills, abilities of creative activity in various arts.

5. Music - supports acquaintance of pupils with the world of music, achievements of national and world musical art, development of their musical abilities and talents.

6. Movement and sports - provides the support for the physical development of schoolchildren in the process of mastering various sports, the formation of their personality, physical culture and healthy lifestyle skills [7].

It is the direct responsibility of every educational institution in the canton of Basel to organize additional support and accompaniment of schoolchildren according to their specific educational needs and capabilities. These tasks are assigned to the so-called support centers which have been specially created at each secondary school. Their functions include various activities, such as socio-pedagogical, psychological and pedagogical, developmental, correctional and therapeutic, rehabilitation, counseling, etc. based on the integration of the efforts of a wide range of specialists - teachers, special educators, psychologists, social workers, doctors and more. The structure of the center provides a special psychological service, the functions of which are defined by psychological and pedagogical diagnosis of children, study of social, school, extracurricular living conditions, psychological and pedagogical counseling of students, teachers, parents, implementation of psychological and therapeutic measures for children, families etc.

Recently, by the common efforts of school teachers and center specialists it has been created a wide range of additional activities to help students in case of vivid difficulties in the process of fulfilling the standard requirements of the curriculum. The typical range of services provided at secondary school of the canton Basel includes the following:

1) extra classes in German for migrant-pupils;

2) extra curriculum classes in certain subjects for lagging students; 
3) speech therapy correction;

4) correction of psychomotor disorders;

5) correction of dyslexia, dysgraphia, dyscalculia, etc.

These types of work support the achievements of standard learning goals and age standards. Such work is carried out on the basis of individual work plans, which provide for the selection of the most effective forms and means of assistance according to the type of difficulties, the specifics of their manifestation, the level of intensity, etc. [8].

Out of special attention in the work under consideration is the program of complex (integrated) school assistance which has been compiled for schoolchildren with difficulties in adaptation to schooling and integration into school society. It is directed to help and overcome difficulties connected with getting used to the school regime, a new system of requirements, a new social environment and determines a well-thought-out system of actions and activities that allow students to overcome existing problems. The program contains a clearly structured set of group and individual game forms and activities, logical and consistent implementation of which helps students to master the system of school norms, requirements, rules, establish contact with other students and teachers, overcome school anxiety, overcome fear of loneliness and rejection by other students. etc. The program is mostly based on play material, through which children learn about the phenomena of school life, the world of human relationships and establish themselves in a new environment for them. The program includes games and exercises for the general development of children with special educational needs, their adaptation to school life and the environment, gaining experience of interpersonal interaction and more. Thus, the program of comprehensive school support provides prevention or overcoming of maladaptation to the educational process and the social environment of the school [8].

Thus, over the last decade, the Swiss canton of Basel has developed its own model for the realization of the right to education of children with special needs in traditional secondary schools. The specificity of this model lies primarily in the closer integration of the general education system with the special and the delegation of a significant amount of functions of the special school to general education. The activities of the special school are instead limited to focusing on particularly complex cases and situations and complex developmental disorders and serious health problems of children with significant risks to their 
lives and threats to the well-being of others, which require conditions and resources that cannot be realized within secondary school.

\section{Investigated experience of Austria}

Based on the achievements of Germany and Switzerland in providing a barrier-free educational environment for all children, regardless of individual abilities, characteristics, needs, Austria's experience in this field differs somewhat. At the level of each federal state there are laws that protect the rights of children to education regardless of race, social origin, health status, enshrine the right to freedom of choice of children and parents of the type of educational institution. For example, the Carinthia Education Act guarantees the creation of conditions for quality education and social adaptation for all children, as well as correctional assistance through special approaches and methods in the presence of special educational needs of schoolchildren [2].

The school system of this federal state of Austria, after all, like others, is conservative enough, not so flexible as to be quickly transformed, putting into practice new educational trends. It is a rather slow process of evolution from the tradition of differentiated education of children depending on their abilities, peculiarities of development, health defects to integrated, open education for all. As of today, the school legislation of the federal state of Carinthia clearly declares the right to quality education without discrimination and still preserves the tradition of parallel operation of general and special education [2].

At the same time, international trends could not but affect the educational practice of Austria in general and its federal state of Carinthia in particular. The law on education of this land clearly outlines the prospects for the realization of the right of persons with special educational needs to quality education within a single educational space still determines the intensification of the relationship between general and special parts of the education system, strengthening their interaction and cooperation on the integration of educational, upbringing, extracurricular, extracurricular activities, etc.

Forms of interaction between secondary and special schools in this federal state are quite diverse. In particular, today the organization of integrated classes in secondary schools with the involvement of special educational institutions in the educational work, development and implementation of special courses based on their joint efforts for additional pedagogical 
support of students with special educational needs, providing individual correctional assistance to students with disabilities. and developmental disorders by teachers of the relevant profile within the secondary school.

Possibilities of integration of children with special needs into the environment of secondary school in the federal state of Carinthia depend on the nature and degree of manifestation of their disorders, defects, difficulties, intensity of pathological processes, their opportunities for education and upbringing in this type of educational institutions without risks to their health. and threats to the well-being of other students, as well as from the material and technical provision of the relevant educational institution, the availability of the necessary human resources to provide additional pedagogical support, psychological and pedagogical support and correctional assistance to this category of students.

Additional pedagogical assistance to schoolchildren with special education in secondary school is aimed at their support in the process of adaptation to school life and school society, correction, minimization of disorders, developmental defects and their general support in achieving educational goals and standards of the general plan of basic school education. or overcoming existing difficulties. This plan defines the main tasks of the educational process to promote the development of the full range of natural abilities and inclinations of children and youth on the basis of universal values in accordance with their age and individual capabilities.

Humanity, solidarity, tolerance, justice and environmental awareness, etc. are considered to be the key ideals and values of society, and therefore their development and acceptance by children and youth is a prerequisite for their full social integration and life. In this context, the plan of basic school education emphasizes the issues of coexistence within a single community with people with disabilities, disabilities, developmental disorders, etc. and the need to combat bias, ignorance, inadequate compassion, lack of understanding and fear of contact with them in all. spheres of life in general and education in particular. The preface clearly states - «the school should become a meeting place for all children, regardless of the specifics of their individual needs and capabilities» [3].

These objectives are realized in curriculum through the range of school disciplines and courses, through all types of school, educational, developing measures. To the edition to the fact mentioned about, the document 
determines the norms and ranks of comprehensive school in terms of basic secondary education and social education - since social education equals the system of knowledge in fundamental disciplines.

Proper organization of social education, which is indicated in the plans , creates the preconditions for unified education of children with different cognitive abilities, different social backgrounds, different specific needs, etc., and in the future for their harmonious coexistence in a single society. Such requirements of the basic school education plan gradually create the basis for the development of a coherent single school system for all students, regardless of their special needs and disabilities [3].

The general norms of the same plan in the adapted form serve as the basis of the organization of activity of special educational institutions of the federal state of Carinthia. They form the core of their special educational plans and programs, in accordance with the specific educational needs and capabilities of students of special schools and supplemented by appropriate developmental and corrective elements. Therefore, in order to ensure the right to quality education for all, including children with special educational needs, the work of special schools is undergoing significant changes. In addition to adapting their curricula to common school standards, there is also the modernization of other aspects of their activities aimed at overcoming their shortcomings, the key of which is the social segregation of students.

The way to solve this problem in the federal state of Carinthia is paved primarily through close cooperation and cooperation of general and special education institutions, development and implementation of a set of joint mostly extracurricular, extracurricular activities that provide space for constant direct contact between students of secondary and special schools, their mutual knowledge and mutual acceptance. Joint projects of secondary and special schools are seen, on the one hand, as an effective way to solve the problem of social disintegration of children with special needs, and on the other - as an important step towards quality education for all within a single social environment.

Hence, the peculiarities of the experience of Austria in support of social and educational integration of disabled schoolchildren (children with special needs) into common educational environment, as can be seen from the example of the federal state Carinthia, lies in the choice of method of controlled evolutional development, rather than radical revolutionary 
transformations, abandonment of hasty decisions and attempts to achieve immediate results through dubious radical changes, but the preservation of the best traditions of special education for people with special needs in today's conditions, shows prudent actions and measures to address this problem. The uniqueness of Austria's approach lies in identifying opportunities and ways of interaction between general and special education, providing conditions for exchange of experience and achievements between secondary and special schools, assessing the prospects of their full integration to realize the right to education for all within the country's educational space.

\section{Conclusions}

Summing up the information mentioned above, the investigated material and made analysis of foreign experience in ensuring the right for education for all without discrimination in common educational enviroment on the example of German-speaking countries, makes it possible to conclude the following. Guided by international norms, each country still builds up its own model to integrate education with special educational needs into a common educational space in view of its inherent socio-economic conditions, value orientations of state institutions and society, national policy in the field of education, etc. At the stage of implementation, this model is further differentiated at the level of individual regions, administrative units according to their specific local conditions, needs and opportunities.

The analysis shows that the idea of including all children, regardless of physical, mental, intellectual, cultural, ethnic, linguistic, etc. characteristics, in a single general education system has become one of the key priorities of modern international educational policy. Its implementation allows children to realize the abilities, talents, differences and features of each other, to develop social contacts, to form the ability to interact with each other and with the environment.

This approach to the organization of education promotes awareness of one's own personality, regardless of origin, state of health or developmental characteristics of a part of the social community and the formation of a sense of belonging to it. It opens wide prospects for fostering tolerance of students without special educational needs, forming their readiness to accept human differences and respect for diversity, developing the ability to help each other, as well as awareness of the peculiarities and difficulties of life of people with 
disabilities. Instead, for children with special needs, the idea of learning within a single general education system creates the preconditions for fuller realization of development potential, active participation in the school community, and in the long run to occupy a worthy niche in society, reducing social inequality.

The resulting multiplicity of options for the implementation of the right to education without discrimination for people with special needs in the world opens up interesting opportunities and prospects for Ukraine to find its own way to solve this problem. We see prospects for further explorations in the analysis of the peculiarities of the organization of education of schoolchildren with special educational needs in the secondary school of other leading countries of the world.

Prospects for further research include analysis of international trends in the development of education of persons with special educational needs in secondary school.

\section{REFERENCES:}

1. Mukan N., Kozibroda L. (2020). Intehratsiya uchniv z osoblyvymy osvitnimy potrebamy $\mathrm{v}$ seredovyshche zahalnoosvitnoyi shkoly u konteksti mizhnarodnoyi osvitnoyi polityky [Integration of students with special educational needs into the secondary school environment in the context of international educational policy]. Molod i rynok, vol. 3-4(182-183), pp. 40-46.

2. Kärntner Schulgesetz (Fassung vom 09.09.2020). URL: https://www.ris.bka.gv.at/ GeltendeFassung.wxe?Abfrage $=$ LrK\&Gesetzesnummer $=20000025$ (accessed 10 September 2020).

3. Lehrplan der Volksschule vom 13. September 2012. URL: https://www.bmbwf.gv.at/Themen/schule/schulpraxis/lp/lp_vs.html (accessed 10 September 2020).

4. Lehrplan für die Primarstufe der Grundschule. URL: https://lehrplan.lernnetz.de/index.php?wahl=4 (accessed: 4.09.2020).

5. Lehrplan für die Sekundarstufe I der weiterführenden allgemeinbildenden Schulen Hauptschule, Realschule, Gymnasium. URL: https://lehrplan.lernnetz.de/ index.php?wahl $=5$ (accessed 04 September 2020).

6. Schleswig-Holsteinisches Schulgesetz vom 24. Januar 2007. RL: http://www.gesetze-rechtsprechung.sh.juris.de/jportal/?quelle=jlink\&query= SchulG + SH\&psml=bsshoprod.psml\& $\max =$ true $\&$ aiz $=$ true $\# \mathbf{j l}$-SchulGSH 2007V11P5 (accessed 04 September 2020).

7. Schulgesetz des Kantons Basel-Stadt vom 4. April 1929 (Stand 10. August 2020). URL: https://www.gesetzessammlung.bs.ch/app/de/texts_of_law/410.100/ versions/1568 (accessed 08 September 2020).

8. Sonderpädagogisches Konzept für die Kantone Basel-Landschaft und BaselStadt. URL: https://edudoc.ch/record/37945 (accessed 08 September 2020). 